\title{
Influences of Image Communication Paradigm of Sports Information on Sports Behavior of University Students
}

\author{
Jie $\mathrm{Gao}^{1}$ \\ ${ }^{1}$ Physical Education Department, Qingdao University of Science \& Technology, Qingdao, China \\ Correspondence: Jie Gao, Physical Education Department, Qingdao University of Science \& Technology, \\ Qingdao 266061, China. E-mail: gjqust@163.com
}

Received: August 2, 2012 Accepted: August 16, 2012 Online Published: August 30, 2012

doi:10.5539/ass.v8n11p243

URL: http://dx.doi.org/10.5539/ass.v8n11p243

\begin{abstract}
Image communication paradigm is the most important means of sports information dissemination. As mass communication media, TV, video website and other mass media are means that promote the development of modern sport. With a questionnaire survey on university students in non-sports majors, this article analyses influences of image communication paradigm of sports information on exercise behavior of university students, so as to correctly guide sports consciousness and sports behavior of university students, which is likely to lay a solid foundation for letting students form a good habit of physical training and develop lifelong sports consciousness.
\end{abstract}

Keywords: sports information, image communication, university students, sports behavior

Today when sports cause is rapidly developed, continuous increase in the amount of sports information, such as, TV sports programs and sports events broadcasting, has enhanced the important position of the image media means of TV and network in improving sports quality of the public. Such mass media as TV and video website with the communications symbols of image language have also become the most influential means in disseminating sports information. Image communication disseminates sports information through the binary channels of the two symbols of picture and sound and has a direct effect on the visual sense of hearing sense of the public, which enables the public to comprehend sports information in a comprehensive, timely, accurate and specific way and to watch wonderful sports events more intuitively and clearly. University students are the important audience group of sports information and image communication of sports information also affects their sports behaviors all the time. This paper analyzes influences of image communication paradigm of sports information on sports behaviors of university students through a questionnaire survey on full-time non sports students in three universities in Qingdao, so as to correctly guide the sports consciousness and sports behaviors of university students and lay a solid foundation to enable university students to form a good habit of sports exercise and cultivate a life-long sports consciousness.

\section{Research Object and Research Method}

\subsection{Research Object}

We choose full-time non sports students as the research object from the three universities of Qingdao University of Science \& Technology, Qingdao University and Qingdao Technological University.

\subsection{Research Method}

\subsubsection{Study of Document Literature}

With resources in the library in Qingdao University of Science and Technology, the author looked upon approximately 40 articles about dissemination of sports information and sports behaviors of university students from the following journals, such as, China Sport Science, Sports \& Science, China Sport Science and Technology, Journal of Beijing Sport University, Journal of Shandong Institute of Physical Education and Sports and so on. Besides, the author referred to such books as "Sports Behavioral Science", "University Psychological Science", "Introduction to Communication" and "Introduction to Sports". All the above has offered theoretical foundation for research in this paper. 


\subsubsection{Questionnaire Survey}

\subsubsection{Design of Questionnaire}

For requirement of the research content in this paper, this paper designs and distributes "Survey questionnaire about influences of image communication paradigm of sports information on sports behaviors of university students" according to the basic requirements of sociological and statistical analysis and conducts reliability and validity test on the questionnaire.

\subsubsection{Validity and Reliability of Questionnaire}

The survey questionnaire in this paper has been checked and approved by five experts in sports in Ocean University of China and China University of Petroleum and one professor in psychology in Qingdao University of Science and Technology. The content validity complies with requirement of sociology, which is shown in Table 1.

Table 1. Evaluation result of experts on the questionnaire

\begin{tabular}{ccccc}
\hline Opinions of experts & Quite effective & Effective & Common & Ineffective \\
\hline $\begin{array}{c}\text { The number of } \\
\text { people selected }\end{array}$ & 4 & 2 & 0 & 0 \\
Percentage $(\%)$ & 67 & 33 & 0 & 0 \\
\hline
\end{tabular}

This paper adopts test-retest reliability. That is, 100 respondents are surveyed twice, with an interval of two weeks between these two surveys. All data obtained from the two questionnaires are compared and the average value of the correlation coefficient of the two is $r=0.91$. The result shows that the reliability is relatively high, which complies with the requirement of the survey questionnaire.

\subsubsection{Distribution and Recovery of Questionnaire}

The survey questionnaire was distributed on November 2011 and was taken back on December 2011. The recovery situation of the questionnaire is shown in Table 2.

Table 2. Recovery of the questionnaire

\begin{tabular}{cccccc}
\hline University & $\begin{array}{c}\text { Amount of } \\
\text { distribution }\end{array}$ & $\begin{array}{c}\text { Amount of } \\
\text { recovery }\end{array}$ & $\begin{array}{c}\text { Recovery rate } \\
(\%)\end{array}$ & $\begin{array}{c}\text { Effective } \\
\text { amount }\end{array}$ & $\begin{array}{c}\text { Effective rate of } \\
\text { distribution (\%) }\end{array}$ \\
\hline $\begin{array}{c}\text { Qingdao University of } \\
\text { Science and Technology }\end{array}$ & 140 & 136 & 97.14 & 131 & 93.57 \\
Qingdao University & 140 & 138 & 98.57 & 137 & 97.86 \\
$\begin{array}{c}\text { Qingdao Technological } \\
\text { University }\end{array}$ & 140 & 135 & 96.43 & 130 & 92.86 \\
Total & 420 & 409 & 97.38 & 398 & 94.76 \\
\hline
\end{tabular}

1.2.2.4 Basic Condition of Respondents

Table 3. Distribution of grades and proportion of gender of respondents

\begin{tabular}{cccccc}
\hline Grade & Number & $\begin{array}{c}\text { Number of } \\
\text { male students }\end{array}$ & $\begin{array}{c}\text { Number of } \\
\text { female } \\
\text { students }\end{array}$ & $\begin{array}{c}\text { Proportion of male } \\
\text { students (\%) }\end{array}$ & $\begin{array}{c}\text { Proportion of female } \\
\text { students (\%) }\end{array}$ \\
\hline Freshman & 132 & 87 & 45 & 65.91 & 34.09 \\
Sophomore & 138 & 85 & 53 & 61.59 & 38.41 \\
Junior & 128 & 86 & 42 & 67.19 & 32.81 \\
Total & 398 & 258 & 140 & 64.82 & 35.18 \\
\hline
\end{tabular}

1.2.3 Mathematical Statistical Method

We use EXCEL and SPSS statistical software to input data collected from the survey questionnaires recovered and make statistics of the percentage of the data and process the data with relevant application programs.

\section{Result and Analysis}

Sports behavior is one kind of social behaviors. Chinese scholar Liu Yimin explains sports behavior in his 
"Sports Behavior Science" as an activity by human beings to make use of all sorts of means and methods with a purpose and intention to satisfy a certain kind of sports need. It is a generally broad concept. That is to say, any behavioral activity that has connection with sports can be termed as sports behavior. These activities not only contain the major manifestation form of sports behavior --- movement behavior, but also contain behavior activities of organization, management, publicity, scientific research, teaching, consumption and appreciation of sports. (Liu Yimin, 1993) Among the audience of sports information, university students obtain sports information mainly through the image communication channel of network video or TV. The image communication paradigm of sports information constantly affects and changes the cognitive mode and behavior intention of university students towards sports by means of the sports information environment created by its broad popularity and strong penetrability.

\subsection{Influences on the Desire of University Students to Participate in Sports Exercise}

According to the theory of media need, need is the basis for generation of motive and motive is the manifestation of need. When need is directed at a certain target, manifests the possibility of achieving the target and possesses the approach and mode to satisfy the need, the motive is generated, which becomes the motive power for the activities (Zhang Jingying, 1986). As for sports information, compared with purely text description, without doubt, image communication offers more specific and appreciable information receiving occasion for university students. In image communication, visual sense and hearing sense work simultaneously, which has more obvious influences on the sports psychology of university students.

It is shown (see Table 4) in the survey on "The intention to participate in sports activities after watching a sports event" of university students, there are 122 students who "have a strong intention", accounting for $30.65 \%$ of the total population of students; there are 148 students who "have the intention to participate", accounting for $37.19 \%$ of the total population; there are 128 students who express that "they only want to watch but do not want to participate", accounting for $32.16 \%$ of the total population of students. As a result of gender difference and different recognition in sports by different genders, there are 79 female students among the 128 students. Due to different sports environment surrounding male and female students, there is also a great difference between their intentions to participate in sports activities. However, considering all the data, it can be found that a great majority of university students may have different degrees of intention to participate in sports activities. It proves that, dissemination of sports events with the method of image can not only stimulate the desire of university students to participate in sports activities, but can also motive university students' interest and enthusiasm in participation in sports activities, so as to further meet university students' demand on sports.

Table 4. The intention to participate in sports activities after watching a sports event

\begin{tabular}{cccc}
\hline & $\begin{array}{c}\text { having a strong } \\
\text { intention }\end{array}$ & $\begin{array}{c}\text { Having the } \\
\text { intention }\end{array}$ & $\begin{array}{c}\text { Only like to watch but not want } \\
\text { to participate }\end{array}$ \\
\hline Number (Male/Female) & $96 / 26$ & $113 / 35$ & $49 / 79$ \\
Proportion (\%) & $37.20 / 18.57$ & $43.80 / 25$ & $19 / 56.43$ \\
Total number & 122 & 148 & 128 \\
$\begin{array}{c}\text { Proportion to the total number } \\
\text { (\%) }\end{array}$ & 30.65 & 37.19 & 32.16 \\
\hline
\end{tabular}

\subsection{Influences on University Students'Sports Movement Skills}

University students are a major force among the audience of sports information, so all kinds of sports events both at home and abroad can absorb their attention to different degrees, such as, all kinds of league matches and cup matches of football and basketball. University students are able to grasp movement skills during their stay at the university by a variety of approaches, such as, sports class, sports club and extracurricular activity and so on. Yet, sports skills are disseminated to university students' sense organ through image communication and have a strong stimulus on university students' intention to participate in sports activities. For example, the dazzling dribbling and dribble-drive attack and accurate shoot in football and basketball matches and wonderful moments in the matches constantly stimulate the emotion of sense organ of university students and motive their strong desire to simulate.

It is shown (see Table 5) in the survey on "Influences of watching sports image on grasping the movement skills" of university students, there are 121 students who "simulate the technical movement of sports stars", accounting for $30.40 \%$ of the total population of students; there are 120 students who "learn new technical movements", accounting for $30.15 \%$ of the total population of students. This proves that a large majority of university students 
are affected by the sports events and will actively simulate or learn technical movements, so as to improve their movement skills. However, there are 104 students who "only focus on sports events but their movement skills are not affected", accounting for $26.13 \%$ of the total population of students, there are 53 students who "do not focus on sports events", accounting for $13.32 \%$ of the total population of students. In the above two options, the number of female students is large, respectively 51 female students and 28 female students, which indicates that the thirst for knowledge in movement skills among female students is far away from the thirst of male students. This is not only due to difference of gender, but more due to laggard building of sports environment of universities.

Table 5. Influences of watching sports image on grasping movement skills

\begin{tabular}{|c|c|c|c|c|}
\hline & $\begin{array}{l}\text { Simulate skills } \\
\text { and movement of } \\
\text { sports starts }\end{array}$ & $\begin{array}{l}\text { Learn new } \\
\text { technical } \\
\text { movement }\end{array}$ & $\begin{array}{l}\text { Only focus on } \\
\text { sports events, not } \\
\text { affected in the } \\
\text { movement skills }\end{array}$ & $\begin{array}{l}\text { Not focus on } \\
\text { sports events }\end{array}$ \\
\hline Number (male/female) & $93 / 28$ & $87 / 33$ & $53 / 51$ & $25 / 28$ \\
\hline Proportion (\%) & $36.05 / 20$ & $33.72 / 23.57$ & $20.54 / 36.43$ & $9.69 / 20$ \\
\hline Total number & 121 & 120 & 104 & 53 \\
\hline $\begin{array}{l}\text { Proportion to the total } \\
\text { number }(\%)\end{array}$ & 30.40 & 30.15 & 26.13 & 13.32 \\
\hline
\end{tabular}

\subsection{Influences on University Students' Selection of Movement Items}

According to the theory of communication studies, although the mass media have no authority to determine how the audiences think, they have great influences on what is in the mind of the audiences. Similarly, to a certain extent, image communication of sports events can guide the attention of university students and become a focus of attention. For example, the sports channels in the TV media and network video resources make the interests of university students in a certain movement present a spiral rising mode. Through a statistics on "Broadcasting sports events in the sports channel of CCTV-5" in 2011, broadcasting of football matches was relatively frequent, and matches of table tennis, tennis ball, badminton and track and field events also increase. The public engaged in table tennis and badminton have a good foundation matches and these items are easy to grasp, not restrained by the sports occasion. Broadcasting of World Table Tennis Championships and Sudirman Cup makes more and more people show favor for these two sports items. Ever since the Athens Olympic Games in 2004 when Li Ting and Sun Tiantian gained the double woman champion, the table tennis match has been gradually recognized by the people all over the country after report of the media. Keeping foothold at the international woman table tennis forum by such excellent athletes as Li Na, Zheng Jie, Peng Shuai, and Yan Zi, and holding of Beijing Zhongwang, Shanghai Maters competition, and Guangzhou Female Open Tennis Championship similarly have made table tennis competition become an upsurge in all big cities across the country. After successful holding of Beijing Olympic Games, the media began to concentrate on a variety of track and field events and a multitude of track and field sports stars have become the focus of attention by the media. At the time when people pay attention to contest between Liu Xiang and Dayron Robles and the world record by Bolt, they have also gradually come to know all kinds of track and field events.

With expanded broadcasting of sports movements and events by all kinds of sports media, more and more sports movements and events have been recognized and known by people. It is shown (see Table 6) in the survey of "influences of watching sports image on university students' participation in sports activities", there are 135 students who "would increase the frequency in participating in sports activities" (including 121 male students and 14 female students), accounting for $33.92 \%$ of the total population of students; there are 112 students who "would increase the frequency in participating sports activities during the broadcasting of sports events" (including 89 male students and 23 female students), accounting for $28.14 \%$ of the total population of students. The above two statistical results indicate that a large majority of male students would increase the frequency in participating in sports activities under the influence of sports events, while female students are not affected greatly. There are respectively 78 students and 73 students who "occasionally participate in sports activities" and who "do not participate in sports activities", respectively accounting for $19.60 \%$ and $18.34 \%$ of the total population of students. Female students account for a larger proportion and male students account for a smaller proportion, which indicates that most female students only appreciate sports events, while most male students convert what they have watched into personal actions. 
Table 6. Influences of watching sports image on university students' participation in sports activities

\begin{tabular}{ccccc}
\hline & $\begin{array}{c}\text { Increase the } \\
\text { frequency in } \\
\text { participating in } \\
\text { sports activities }\end{array}$ & $\begin{array}{c}\text { Increase the frequency in } \\
\text { participating in sports } \\
\text { activities during the } \\
\text { broadcasting of the sports } \\
\text { events }\end{array}$ & $\begin{array}{c}\text { Occasionally } \\
\text { participating } \\
\text { in sports } \\
\text { activities }\end{array}$ & $\begin{array}{c}\text { Not } \\
\text { participating in } \\
\text { sports activities }\end{array}$ \\
\hline $\begin{array}{c}\text { Number (Male students } / \\
\text { female students) }\end{array}$ & $121 / 14$ & $89 / 23$ & $23 / 55$ & $25 / 48$ \\
$\begin{array}{c}\text { Proportion (\%) } \\
\text { Total number of students } \\
\text { Proportion to the total } \\
\text { number (\%) }\end{array}$ & $46.90 / 10$ & $34.50 / 16.43$ & $8.92 / 39.29$ & 78 \\
$73.68 / 34.28$ \\
73
\end{tabular}

\subsection{Influences on University Students'Sports Consumption Behavior}

Sports consumption structure refers to the relationship of proportion of all different types of sports consumption materials consumed in the process of sports consumption under a certain social and economic condition. It is the specific reflection of certain sports consciousness and consumption level. As university students are fashionable and vanguard in thinking and have strong thirst of knowledge in new objects, they have strong dependence on consumption. It is shown (see Table 7) in the survey about "major modes of sports consumption by university students", the proportion of university students who choose such entertainment consumption as sportswear, newspapers and periodicals and audio-visual products is large, respectively accounting for $53.77 \%$ and $20.85 \%$, while the proportion of students who choose other consumption modes is small.

Table 7. The major modes of sports consumption by university students

\begin{tabular}{cccccc}
\hline & $\begin{array}{c}\text { Sportswear } \\
\text { (shoes, cap) }\end{array}$ & $\begin{array}{c}\text { Newspaper and } \\
\text { periodicals and } \\
\text { audio-visual product }\end{array}$ & $\begin{array}{c}\text { Entrance ticket } \\
\text { for sports } \\
\text { exercise } \\
\text { stadium }\end{array}$ & $\begin{array}{c}\text { Entrance ticket } \\
\text { for watching a } \\
\text { sports match }\end{array}$ & $\begin{array}{c}\text { Participation in } \\
\text { professional skill } \\
\text { training of sports }\end{array}$ \\
\hline $\begin{array}{c}\text { Number of } \\
\text { students } \\
\text { Proportion } \\
(\%)\end{array}$ & 214 & 83 & 28 & 54 & 19 \\
\hline
\end{tabular}

As university students are not sufficiently mature in their mental intelligence, have not formed a complete and stable consumption concept and have no strong capacity of self-control over their consumption, they are likely to be affected by the publicity of the media or the surrounding friends and, therefore, generate irrational consumption behaviors. Whether advertisements in a variety of live network stations and TV stations or costumes in competition by sports stars can attract university students to purchase them. It is shown (see Table 8) in the survey of "influences of watching sports image on sports consumption of university students", there are 98 students who "would increase consumption", and 145 students who "would increase consumption with selection", respectively accounting for $24.62 \%$ and $36.43 \%$ of the total population of students. Nevertheless, there are also 155 students who choose "not to increase consumption", which accounts for $38.95 \%$ of the total population of students. This indicates that image communication of sports information, to a large extent, has a certain guiding effect on the sports consumption of university students, such as, advertisements on sports products in sports programs, propaganda of sports products in network video and sports equipment of star players, etc. As for university students, especially sports enthusiasts and idolaters of sports stars, excessive pursuit of favors of sports stars might lead to blind consumption, which may affect the sports values of university students.

Table 8. Influences of watching sports image on sports consumption of university students

\begin{tabular}{cccc}
\hline & Increase consumption & Increase consumption with selection & Not increase consumption \\
\hline Number of students & 98 & 145 & 155 \\
Proportion (\%) & 24.62 & 36.43 & 38.95 \\
\hline
\end{tabular}




\subsection{Influences on Sports Consciousness of University Students}

With approaching of the knowledge and economy era with the major characteristics of informationization, digitalization and networking, the sports mass dissemination that regards purely competitive sports as the dissemination object is misleading people's understanding in sports as a sort of culture (Deng Xinghua, 2005). Sine university students are not totally mature in their mental intelligence, they are likely to be affected by some negative influences of sports image, such as, sports image mass media information with violence in the sports occasion, information about bad habits of all kinds of sports stars, and reports on soccer fraud and black whistle, etc. A whoop and a holler of the above phenomena will have negative influences upon the sports value orientation of university students. A wrong impression may be generated among some university students that it is rational that sports stars pursue materials, are special in a famous brand and concentrate on sharing, etc. It is also likely to make some university students have one-sided understanding in the sports phenomena and sports implication and may have doubt in fair and justified sports spirit. Affected by the above delinquent sports media information, university students may be unconsciously affected and their ideological behaviors may be seriously influenced. It is shown (see Table 9) in the survey about "views on delinquent behaviors of violent events, fraud soccer and black whistle in dissemination of sports image", there are 173 students who think "it is interesting", accounting for $43.47 \%$ of the total population of students; there are 79 students who "are worrisome", accounting for $19.85 \%$ of the total population of students; there are 81 students who "are biased towards sports", accounting for $20.35 \%$ of the total population of students; there are 65 students who "don't care", accounting for $65 \%$ of the total population of students. The above data indicate that, for most of university students, the delinquent phenomena of sports are much attractive than wonderful sports competition, and are "more interesting". In the past few years, with economic development in China, people's social and economic concepts have taken great changes, which, in the meantime, has triggered happening of these abnormal social phenomena. In the face of these abnormal phenomena, university students may have incorrect sports consciousness and sports behaviors if they are not correctly guided.

Table 9. View on delinquent conducts of violent events and soccer fraud and black whistle in broadcasting of sports image

\begin{tabular}{ccccc}
\hline & Interesting & Worrisome & Biased towards sports & Don't care \\
\hline Number & 173 & 79 & 81 & 65 \\
Proportion (\%) & 43.47 & 19.85 & 20.35 & 16.33 \\
\hline
\end{tabular}

\section{Conclusion and Suggestions}

\subsection{Conclusion}

It is discovered through the above research that image communication paradigm of sports information has certain facilitating effect on university students' desire to participate in sports exercise, enhancing their movement skills and extending their movement duration of time. Communication of image is able to arouse university students' sense of participation in sports, whereas the mode of participation in sports by means of personal exercise by university students can again strengthen university students' focus of attention on image communication of sports information. These two have a benign interactive relationship.

At the same time, image communication paradigm of sports information has certain directing effect on the sports consumption behavior of university students. Granting a status is an extremely explicit function reflection among the social functions of mass media communication. Image communication elevates a variety of sports consumption brands to a certain degree of reputation and attracts the purchase behavior of university students. Nevertheless, at the same time, the intuitive effect and potential influence of image communication may also lead to blind consumption of university students, makes them excessively depend on the effects of sports consumption products on their sports behavior and sports status and affects their sports values.

In the process of image communication of sports information, the proportion of simulation in the sports behavior of university students should not be ignored. Some negative information of image communication may produce functional disturbance, to some extent, in the sports consciousness of university students, which is mainly manifested in simulation of some delinquent sports behaviors by university students and biased understanding in some delinquent phenomena in sports information.

\subsection{Suggestions}

1) With regards to some negative sports information on the internet, it is necessary to pay attention to forming a discussion atmosphere, guide university students in looking at these sports phenomena in a comprehensive way, 
gradually form their own viewpoints in the process of discussion and finally set up correct and healthy sports consciousness.

2) We need to strengthen sports environment construction on the campus, make rational use of image communication platform to develop all kinds of competitive sports activities and enrich campus sports culture.

3) It is necessary to strengthen positive propaganda vigor of sports stars and mass media, make rational use of the "opinion leader" status of sports stars in the sports consciousness and sports concept of university students, integrate the viewpoint of "life-long sports" into daily dissemination of sports information and stimulate and improve the sports behavior of university students.

4) It is also necessary to reinforce sports teaching and administration in universities, concentrate on teaching reform of sports class, integrate sports resources and enhance service level of sports.

\section{References}

Deng, Xinghua. (2005). Study of Modern Sports Communication. China Sport Science, 25(10), 23-32.

Li, Bin. (1993). Introduction to Communication. Beijing: Xinhua Publishing House.

Liu, Yimin. (1993). Sports Behavior Science. Beijing: People's Sports Publishing House of China.

Yang, Wenxuan, \& Yang, Ting. (2005). Introduction to Sports. Beijing: China Higher Education Press.

Zhang, Jingying. (1986). Scholastic Psychology. Beijing: Tsinghua University Press. 